\title{
Antimicrobial susceptibility pattern of Neisseria gonorrhoeae isolated from fertile and infertile women
}

\author{
Susan Azizmohammadi and Sima Azizmohammadi* \\ Department of Gynecology, Hajar Hospital, AJA University of Medical Sciences, Tehran, Iran
}

*For correspondence: Email: sam_215pv@yahoo.com; Tel: 00989121057715

Received: 30 June 2016

Revised accepted: 9 November 2016

\begin{abstract}
Purpose: To study the prevalence of Neisseria gonorrhoeae in the high vaginal swab samples of fertile and infertile women who were referred to Infertility and Sterility Hospitals, Tehran, Iran as well as investigate their antibiotic resistance pattern.

Methods: Three hundred and twenty high vaginal swabs were taken from fertile and infertile women. The samples were cultured and those that were $N$. gonorrhoeae-positive subjected to the disk diffusion susceptibility test.

Results: Prevalence of N. gonorrhoeae in fertile and infertile women were 5.26 and $16.92 \%$, respectively. All isolates harbored orf1 gene. Patients in the age bracket $>40$ years were at high risk. $\mathrm{N}$. gonorrhoeae strains showed high level resistance against ampicillin (87.5\%), ciprofloxacin (75\%), tetracycline $(71.87 \%)$ and penicillin $(68.75 \%)$.

Conclusion: The possible role of resistant $N$. gonorrhoeae as pathogens causing female infertility constitutes an important finding of the study. The high levels of bacterial resistance against ampicillin, ciprofloxacin, tetracycline, penicillin and spectinomycin, should be taken into account in developing any new guidelines in the management of the infection.
\end{abstract}

Keywords: Neisseria gonorrhoeae, Female infertility Drug Resistance, Ciprofloxacin, Tetracycline, Spectinomycin

Tropical Journal of Pharmaceutical Research is indexed by Science Citation Index (SciSearch), Scopus, International Pharmaceutical Abstract, Chemical Abstracts, Embase, Index Copernicus, EBSCO, African Index Medicus, JournalSeek, Journal Citation Reports/Science Edition, Directory of Open Access Journals (DOAJ), African Journal Online, Bioline International, Open-J-Gate and Pharmacy Abstracts

\section{INTRODUCTION}

Infertility is one of the major serious concerns confronting medical practitioners. Despite all the advances in medical sciences, the main reasons of infertility especially in women are still unknown. Infertility means that couples have been trying to get pregnant with frequent interaction for at least a year with no achievement [1,2]. It has been estimated that about 72.4 million couples are infertile [3]. Majority of women with infertility problems manifest inflammatory changes of the oviduct or surrounding peritoneum. Most of these alterations result from infections [4].
Neisseria gonorrhoeae (the gonococcus) is a Gram-negative diplococcal bacterium which infects only humans. It causes gonorrhea, sexually transmitted infections (STI), Pelvic Inflammatory Disease (PID), ectopic pregnancy, chronic pelvic pain, infertility, acute urethritis, cervicitis and proctitis or pharyngitis [5]. $N$. gonorrhoeae infections represent 106 million of the estimated 498 million new cases of curable sexually transmitted infection that occur globally every year [5]. Previous studies have estimated 3.4 million cases of gonorrhea among adults in the European countries [5]. 
One of the best therapeutic options for treatment of the cases of gonorrhea caused by this bacterium is antibiotic therapy. However, antibiotic-resistant $N$. gonorrhoeae have evolve and spread rapidly [6]. N. gonorrhoeae resistance is commonly observed with penicillin, tetracycline and fluoroquinolones antibiotics [6]. Resistance has also emerged against cefixime, an oral third generation cephalosporin, in recent years $[7,8]$. Since 2010 , cefixime has not been recommended as first-line drug treatment $[7,8]$ following $\mathrm{WHO}$ guidelines, stating that an antibiotic should not be used when more than 5 $\%$ of $N$. gonorrhoeae isolates are resistant [9]. Injectable ceftriaxone, in combination with oral azithromycin, are the recommended first line drug treatment [10]. Data regarding the epidemiology, prevalence of antibiotic resistance profile of $N$. gonorrhoeae in the cases of female infertility is scarce in Iran. Therefore, the present investigation was carried out to study the prevalence of $N$. gonorrhoeae in the high vaginal swab samples of fertile and infertile women as well as investigate the antibiotic resistance pattern of bacterial isolates.

\section{EXPERIMENTAL}

\section{Ethical issues}

The aspect of human studies in the present study was approved by the ethical committee of Department of Infertility and Sterility of Educational Hospitals, Iran (approval ref no. 20275 MD), and the Research Adjutancy of Hajar Hospital, Tehran, Iran (approval ref no. 45891 $\mathrm{MD})$. The authors conformed to generally accepted scientific principles [11]. All samples were taken from volunteer women who were referred to Infertility and Sterility Hospitals, Iran. Written consents were obtained from the infertile and fertile women or their husbands.

\section{Sample collection}

Samples were collected from June to November 2015; a total of 130 high vaginal swab specimens were taken from infertile women. In a primary view, a woman after a year of regular intercourse without prevention was defined as infertile. Vaginal specimens were collected from the ventral fornix without any contact with urine and external parts of reproductive system using speculum and commercial sterile cotton-tipped swabs. All specimens were collected by an expert midwife. One hundred and ninety vaginal swab specimens were also collected from fertile women with no history of infertility.

\section{Culture-based identification of $\boldsymbol{N}$. gonorrhoeae}

All the samples were inoculated directly onto modified Thayer Martin (Thayer Martin + laked sheep blood and the antibiotic supplement (BBL VCNT inhibitor) including colistin $(750 \mu \mathrm{g})$, nystatin (1250 units), vancomycin $(300 \mu \mathrm{g})$ and trimethoprim Lactate $(500 \mu \mathrm{g})$ ) and incubated immediately at 34 to $36^{\circ} \mathrm{C}$ in an atmosphere of 5 $\% \mathrm{CO}_{2}$ for $72 \mathrm{~h}$. Morphologically suggestive colonies were screened by Gram staining and by their positive responses to the oxidase and catalase tests. Positive colonies were subcultured on chocolate supplement agar (Chocolate Polyvitex/Biomérieux ${ }^{\circledR}$ ), and their identification confirmed by fluorescent-antibody staining (Baxter Scientific, McGaw Park, III).

\section{DNA extraction and PCR confirmation of positive colonies}

Genomic DNA was extracted from the bacterial colonies using the commercial genomic DNA extraction kit (Fermentas, Germany) according to the manufacturer's instruction. The DNA concentration has been determined by measuring absorbance of the sample at $260 \mathrm{~nm}$ using spectrophotometer [12]. Presence of $N$. gonorrhoeae was confirmed with the PCR-based amplification of orf1 gene. Reaction was performed in a final volume of $50 \mu \mathrm{L}$ containing 5 $\mu \mathrm{L} 10 \times$ buffer $+\mathrm{MgCl}_{2}, 2 \mathrm{mM}$ dNTP, 2 unit Taq DNA polymerase, $100 \mathrm{ng}$ genomic DNA as a template, and 25 picomole of each primer (5'CAACTATTCCCGATTGCGA-3' and 5'GTTATACAGCTTCGCCTGAA-3') (amplify the 221-480 bp region of orf1 gene). PCR was performed using a thermal cycler (Eppendorf Mastercycler 5330, Eppendorf-Nethel-Hinz $\mathrm{GmbH}$, Hamburg, Germany) under the following conditions: an initial denaturation for $10 \mathrm{~min}$ at 94 ${ }^{\circ} \mathrm{C}$ and 40 cycles including $94^{\circ} \mathrm{C}$ for $30 \mathrm{~s}, 52{ }^{\circ} \mathrm{C}$ for $30 \mathrm{~s}$ and $72{ }^{\circ} \mathrm{C}$ for $1 \mathrm{~min}$, and a final extension at $72{ }^{\circ} \mathrm{C}$ for $5 \mathrm{~min}$. S. aureus ATCC 19424 was used as a positive control and distilled water was used as a negative control. PCR amplification products $(15 \mu \mathrm{l})$ were subjected to electrophoresis in a $2 \%$ agarose gel in $1 \mathrm{X}$ TBE buffer at $80 \mathrm{~V}$ for $30 \mathrm{~min}$, stained with SYBR Green.

\section{Evaluation of antimicrobial susceptibility pattern of $\mathbf{N}$. gonorrhoeae}

Pattern of antimicrobial resistance was studied using the simple disk diffusion technique. Antibiotic resistance of the $N$. gonorrhoeae strains against 9 commonly used antibiotics was determined using the Clinical and Laboratory 
Standards Institute guidelines [20]. Susceptibility of $N$. gonorrhoeae isolates were tested against ampicillin (10 $\mu \mathrm{g} /$ disk), azithromycin (15 $\mu \mathrm{g} / \mathrm{disk})$, cefixime (5 $\mu \mathrm{g} / \mathrm{disk})$, ceftriaxone (30 $\mu \mathrm{g} / \mathrm{disk}$ ), ciprofloxacin (5 $\mu \mathrm{g} /$ disk), chloramphenicol (30 $\mu \mathrm{g} /$ disk), penicillin (10 $\mathrm{u} /$ disk), tetracycline (30 $\mu \mathrm{g} /$ disk) and spectinomycin (100 $\mu \mathrm{g} / \mathrm{disk})$ antibiotic agents (Oxoid, UK). The diameter of the zone of inhibition produced by each antibiotic disc was measured and interpreted using the CLSI zone diameter interpretative standards [13]. N. gonorrhoeae ATCC 49226 was used as a standard reference strain for quality control of susceptibility testing.

\section{Statistical analysis}

The results were transferred to a Microsoft Excel spreadsheet (Microsoft Corp., Redmond, WA) for analysis. Statistical analysis was performed using SPSS/18.0 software (SPSS Inc, Chicago, IL) for significant relationship between the prevalence of bacteria and their antibiotic resistance pattern. The chi-square test and Fisher's exact 2-tailed test analysis were performed in this study. Statistical significance was regarded at $p<0.05$.

\section{RESULTS}

Table 1 represents the total prevalence of $\mathrm{N}$. gonorrhoeae in fertile and infertile women of Iranian infertility and sterility hospitals. Results showed that 32 out of 320 high vaginal swab samples $(10 \%)$ were positive for $N$. gonorrhoeae. Besides, the prevalence of bacteria in the high vaginal swab samples of fertile and infertile women were 5.26 and $16.92 \%$, respectively. Those older than 40 years old fertile $(20 \%)$ and infertile $(50 \%)$ women had the highest prevalence of $N$. gonorrhoeae. Significant statistical differences were seen for the prevalence of $N$. gonorrhoeae between fertile and infertile women $(p<0.01)$. Statistical difference was also seen between the age of women and prevalence of $N$. gonorrhoeae $(p<$ 0.05 ). All the $N$. gonorrhoeae strains were confirmed using the PCR amplification of orf1 gene (Figure 1). The $N$. gonorrhoeae isolates were positive for the orf1 gene (Table 1).

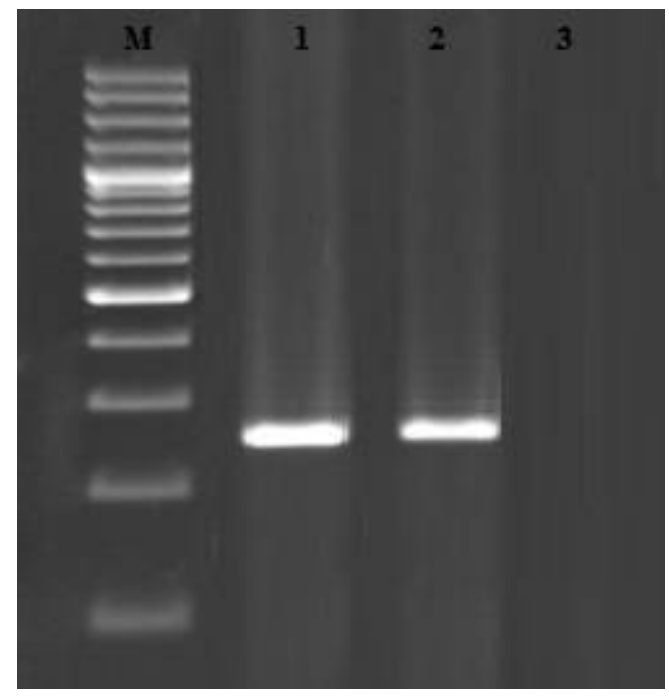

Plate 1: Gel electrophoresis of PCR products for orf1 gene (260 bp). M: 100 bp ladder, 2: Positive sample for the orf1 gene, 2: Positive control and 3: Negative control

Table 2 represents the antimicrobial resistance pattern of $N$. gonorrhoeae strains isolated from fertile and infertile women of Iranian infertility and sterility hospitals. We found that the $N$. gonorrhoeae strains showed high level resistance against ampicillin $(87.5 \%)$, ciprofloxacin $(75 \%)$, tetracycline $(71.87 \%)$ and penicillin $(68.75 \%)$. N. gonorrhoeae isolates of infertile women were more resistant against commonly used antibiotic than those of fertile women $(p<0.05)$.

Table 1: Total prevalence of Neisseria gonorrhoeae in fertile and infertile women in infertility and sterility hospitals in Tehran, Iran

\begin{tabular}{|c|c|c|c|c|}
\hline \multicolumn{2}{|c|}{ Type of sample } & $\begin{array}{c}\text { No. of samples } \\
\text { collected }\end{array}$ & $\begin{array}{c}\text { N. gonorrhoeae (N, } \\
\%)\end{array}$ & $\begin{array}{c}\text { Orf1 gene-positive } \\
(\%)\end{array}$ \\
\hline \multirow{5}{*}{$\begin{array}{l}\text { Fertile } \\
\text { women }\end{array}$} & $<20$ years & 55 & $1(1.81)$ & $1(1.81)$ \\
\hline & $20-30$ years & 65 & $1(1.53)$ & $1(1.53)$ \\
\hline & $30-40$ years & 45 & $3(6.66)$ & $3(6.66)$ \\
\hline & $>40$ years & 25 & $5(20)$ & $5(20)$ \\
\hline & Total & 190 & $10(5.26)$ & $10(5.26)$ \\
\hline \multirow{5}{*}{$\begin{array}{l}\text { Infertile } \\
\text { women }\end{array}$} & $<20$ years & 30 & $4(13.33)$ & $4(13.33)$ \\
\hline & $20-30$ years & 50 & $3(6)$ & $3(6)$ \\
\hline & $30-40$ years & 30 & $5(16.66)$ & $5(16.66)$ \\
\hline & $>40$ years & 20 & $10(50)$ & $10(50)$ \\
\hline & Total & 130 & $22(16.92)$ & $22(16.92)$ \\
\hline \multicolumn{2}{|c|}{ Total } & 320 & $32(10)$ & $32(10)$ \\
\hline
\end{tabular}


Table 2: Antimicrobial resistance pattern of Neisseria gonorrhoeae strains isolated from fertile and infertile women of Iranian infertility and sterility hospitals

\begin{tabular}{|c|c|c|c|c|c|c|c|c|c|}
\hline \multirow{2}{*}{$\begin{array}{l}\text { Type of sample (no. } \\
\text { positive) }\end{array}$} & \multicolumn{9}{|c|}{ Antibiotic resistance pattern (\%) } \\
\hline & AM10 & AZ15 & CFX5 & CTX30 & CIP5 & C30 & P10 & TET30 & SPCT100 \\
\hline Fertile women (10) & $7(70)$ & $1(10)$ & $2(20)$ & - & $6(60)$ & - & $5(50)$ & $6(60)$ & $4(40)$ \\
\hline Infertile women (22) & $21(95.45)$ & $5(22.72)$ & $3(13.63)$ & $2(9.09)$ & $18(81.81)$ & $1(4.54)$ & $17(77.27)$ & $17(77.27)$ & $14(63.63)$ \\
\hline Total (32) & $28(87.5)$ & $6(18.75)$ & $5(15.62)$ & $2(6.25)$ & $24(75)$ & $1(3.12)$ & $22(68.75)$ & $23(71.87)$ & $18(56.25)$ \\
\hline
\end{tabular}

\section{DISCUSSION}

Infections of the genital tract may be predisposing factors in unexplained infertility. Hormonal disorders that occurred in infertile women can lead to reduced levels of immunity and increase bacterial colonization of vaginal epithelium [14]. Women follicular fluid is not sterile and the levels of cytokines, chemokines and growth factors which are essential for ovarian function [15], secretion of ovarian steroid hormones [15] and development and regression of corpus luteum [16] in follicular fluid of infertile women have been decreased. Therefore, it is not surprising the $16.92 \%$ of high vaginal swab samples of infertile women were infected with resistant strains of $N$. gonorrhoeae. The present study found high levels of $N$. gonorrhoeae resistance against ampicillin, ciprofloxacin, tetracycline, penicillin and spectinomycin.

Several investigations have been done in this field all-around the world. Afrasiabi et al [17] reported that gonorrhea was diagnosed in 7 out of $294(2.38 \%)$ Iranian women which was lower than our results. They showed that the highest levels of resistance was observed for ciprofloxacin (100\%), penicillin G (100\%), ceftriaxone (100\%) and cefepime (100\%), but $28.5 \%$ of isolates showed intermediate sensitivity to tetracycline. Significantly lower prevalence of $N$. gonorrhoeae were also found among Iranian previously published research [18]. Brunner et al [19] reported that among the 9097 sexually active patients tested, 582 had an $N$. gonorrhoeae infection (6.39\%). The isolates were all sensitive to ceftriaxone and spectinomycin and 581/582 strains were sensitive to cefixime (99.82 \%). They also showed a high percentage of detected resistance to penicillin (77\%), tetracycline (86\%), and ciprofloxacin (66\%) which are similar to our findings.

In Iran, as is the case in many other countries, the control of gonococcal infections mostly depended on an effective single-dose antibiotic therapy given at the first clinical presentation of the patient. Prior knowledge of the antimicrobial susceptibility pattern of the particular strain infecting the patient was routinely not established however. With increasing evidence of antimicrobial resistance in gonococcal infections there was a real risk of treatment failure and development of further resistance to antibiotics.

Unfortunately, irregular and indiscriminate prescription of some routine antibiotics including ampicillin, ciprofloxacin, tetracycline, penicillin and spectinomycin in Iranian infertility and sterility hospitals caused high level resistance against them. High prevalence of gonococcal resistance against these antibiotics has been reported previously from United States [20] and United Kingdom [21]. Wit was found that $3.12 \%$ of $N$. gonorrhoeae strains were resistant against chloramphenicol. Chloramphenicol is only used in the final stages of treatment when other therapeutic agents are not effective, hence a low level of resistance against this antibiotic.

\section{CONCLUSION}

The results of this study highlight the role of $N$. gonorrhoeae as a possible pathogens of infertility in women, and are a significant contribution to current knowledge on antimicrobial susceptibility of $N$. gonorrhoeae strains isolated from cases of infertility in Iran. A high level of antimicrobial resistance has been found in the isolated strains. The emergence of resistance against currently recommended antibiotics is worrisome.

Thus, rapid identification of cases of gonococcal female infertility, and also primary treatment with ceftriaxone, cefixime, and azithromycin, and in severe cases with chloramphenicol, may reduce the risk of further complications. Monthly checkup of fertile women and treatment with appropriate antibiotics may reduce the risk of infertility. Changes in the pattern of antibiotic resistance should be taken into account in developing any new treatment guidelines for the infection.

Trop J Pharm Res, December 2016; 15(12): 2656 


\section{DECLARATIONS}

\section{Conflict of Interest}

No conflict of interest associated with this work.

\section{Contribution of Authors}

The authors declare that this work was done by the authors named in this article and all liabilities pertaining to claims relating to the content of this article will be borne by them.

\section{Open Access}

This is an Open Access article that uses a funding model which does not charge readers or their institutions for access and distributed under the terms of the Creative Commons Attribution License (http://creativecommons.org/licenses/by 14.0) and the Budapest Open Access Initiative (http://www.budapestopenaccessinitiative.org/rea d), which permit unrestricted use, distribution, and reproduction in any medium, provided the original work is properly credited.

\section{REFERENCES}

1. Jensen JS. Mycoplasma genitalium infections. Diagnosis, clinical aspects, and pathogenesis. Dan Med Bull 2006; 53(1): 1-27.

2. Yahaghi E, Imani Fooladi AA, Amin M, Mirnejad R, Nezamzade R, Amani J. Detection of Class I Integrons in Staphylococcus aurous Isolated from Clinical Samples Iran Red Crescent Med J 2014; 16(11): e16234.

3. Boivin J, Bunting L, Collins JA, Nygren KG. International estimates of infertility prevalence and treatment-seeking: potential need and demand for infertility medical care. Hum Reprod 2007; 22(6): 1506-1512.

4. Wiesenfeld HC, Hillier SL, Meyn LA, Amortegui AJ, Sweet $R L$ Subclinical pelvic inflammatory disease and infertility. Obstet Gynecol 2012; 120: 37-43.

5. Furuya R, Tanaka M. Neisseria gonorrhoeae infections. Nihon Rinsho 2009; 67(1): 129-135.

6. Deguchi T, Nakane K, Yasuda M, Maeda S. Emergence and spread of drug resistant Neisseria gonorrhoeae. J Urol 2010; 184(3): 851-858.

7. Verdon MS, Douglas JM Jr, Wiggins SD, Handsfield HH. Treatment of uncomplicated gonorrhea with single doses of $200 \mathrm{mg}$ cefixime. Sex Transm Dis 1993; 20(5): 290-293.

8. Allen VG, Mitterni L, Seah C, Rebbapragada A, Martin IE, Lee $C$, Siebert $H$, Towns L, Melano RG, Low DE. Neisseria gonorrhoeae treatment failure and susceptibility to cefixime in Toronto, Canada. JAMA 2013; 309(2): 163-170.
9. Davies SC, Fowler T, Watson J, Livermore DM, Walker D. Annual Report of the Chief Medical Officer: infection and the rise of antimicrobial resistance. Lancet 2013; 381: 1606-1609.

10. Ison CA, Town K, Obi C, Chisholm S, Hughes G, Livermore DM, Lowndes CM. Decreased susceptibility to cephalosporins among gonococci: data from the Gonococcal Resistance to Antimicrobials Surveillance Programme (GRASP) in England and Wales, 20072011. Lancet Infect Dis 2013; 13: 762-768.

11. Ethics and research on human subjects: international guidelines. J Med Ethics 1995; 21(6): 363-364. PMCID: PMC1376838.

12. Sambrok JA. Molecular Cloning, A Laboratory Manual. 3rd edition. Cold Spring Harbor Laboratory Press. New York: USA; 2001. p. 2100.

13. Clinical and Laboratory Standards Institute (CLSI). Performance Standards for Antimicrobial Disk Susceptibility Tests, Approved Standard-Ninth Edition (M2-A9). United States: Clinical and Laboratory Standards Institute; 2012.

14. Kornats'ka AH. Local humoral immunity in women with combined forms of infertility. Lik Sprava 1998; (4): 8284.

15. Richards JS, Sharma SC, Falender AE, Lo $Y H$. Expression of FKHR, FKHRL1, and AFX genes in the rodent ovary: evidence for regulation by IGF-I, estrogen, and the gonadotropins. Mol Endocrinol 2002; 16: 580599.

16. Chen Y, Peng Z. Study of estrogen and progesterone receptors in endometrial carcinoma. Hua Xi Yi Ke Da Xue Xue Bao 2000; 31: 98-100.

17. Afrasiabi S, Moniri R, Samimi M, Mousavi SG. The frequency of Neisseria gonorrhoeae endocervical infection among female carrier and changing trends of antimicrobial susceptibility patterns in Kashan, Iran. Iran J Microbiol 2014; 6: 194-197.

18. Baghchesaraei H, Amini B, Hossaini M. Prevalence of infection with Neisseria gonorrhoeae and Chlamydia trachomatis in women visitors of gynecology and obstetrics clinics in Zanjan Province of Iran. African Journal of Microbiology 2011; 5: 2447-2450.

19. Brunner A, Nemes-Nikodem E, Mihalik N, Marschalko M, Karpati S, Ostorhazi E. Incidence and antimicrobial susceptibility of Neisseria gonorrhoeae isolates from patients attending the national Neisseria gonorrhoeae reference laboratory of Hungary. BMC Infect Dis 2014; 14: 433-436.

20. Centers for Disease Control and Prevention (CDC). Cephalosporin susceptibility among Neisseria gonorrhoeae isolates--United States, 2000-2010. MMWR Morb Mortal Wkly Rep 2011; 60(26): 873-877.

21. Bignell $C$, Fitzgerald $M$. UK national guideline for the management of gonorrhoea in adults, 2011. Int J STD AIDS 2011; 22: 541-547. 